DOI: $10.2478 / \mathrm{v} 10077-010-0017-\mathrm{x}$

D. Mężyk

Institute of Power Engineering, Warsaw, Poland; e-mail: dariusz.mezyk@ien.com.pl

\title{
STRUCTURAL MATERIALS USED FOR STEAM PIPELINES IN POWER INDUSTRY
}

\begin{abstract}
The study presents some strength parameters of structural materials, including steel grades 13HMF, P91 and P92, currently used in professional power engineering to produce pipelines, boiler super-heaters, steam tanks, steam pressure tanks and pipelines designed to operate at the temperature range up to $650^{\circ} \mathrm{C}$. The author presented results of material stress tests performed by him for pipelines in as-delivered state as well as after 40000 hours of operation. The tests were made using Mathar strain gauge method. Hardness test results for areas subjected to strain gauge tests and structural changes of tested samples are also presented. Stress test results indicate stress increase for operated material as well as for grain size growth compared to as-delivered material. It is caused by operating load (both thermal and mechanical) of the pipeline material.
\end{abstract}

Key words: degradation, microstructure, stress, pipeline

\section{FACTORS DECREASING LIFETIME OF PIPELINE MATERIAL}

Structural materials degrade over long-time operation when exposed to different environmental conditions and temperatures as well as mechanical load. This degradation changes material microstructure and makes its strength properties worse. Industry practice shows that material degradation has different intensity and that it intensifies at the end of the component life period as a result of its many-years operation in creep conditions. However, one can state that the most characteristic symptoms of material degradation in the $2^{\text {nd }}$ creep phase are structural changes, whereas dominant factor in the $3^{\text {rd }}$ phase become micro-defects leading to development of fractures and to final damage of the material.

Actual lifetime, i.e. remaining period of safe operation of individual components depends on their working conditions. That period is different for different plant components, particularly in case of shaped fixtures. As it is necessary to ensure safe operation of power industry high-pressure pipelines working in high temperatures, they must be made of heat resistant steel of appropriate mechanical properties (yield strength, creep strength) at those temperatures. 


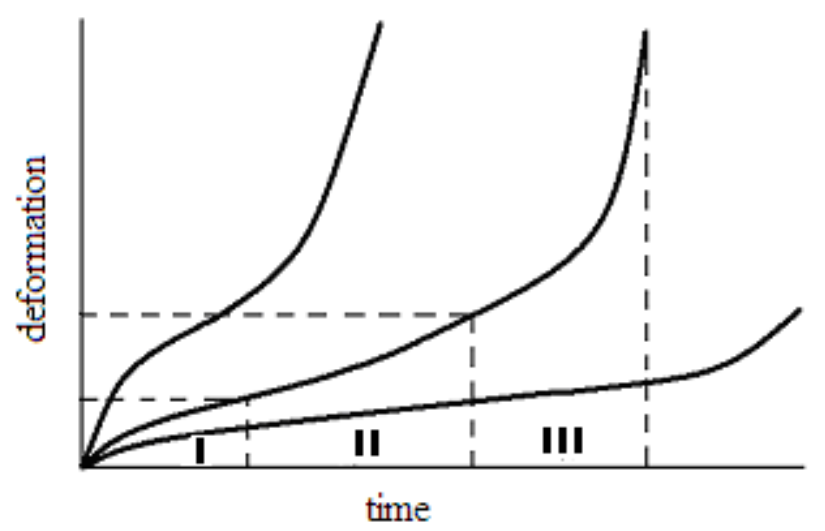

Fig. 1. Steel creep curves

High-pressure pipelines connecting the boiler with the turbine pose high risk during the power plant operation. They form a complex spatial system designed to convey the working agent between the turbine and the boiler. The strength model of the pipeline is a multi-span continuous beam supported on elastic or constant-force spot bearers. The pipeline consists of straight sections connected with shaped components such as arcs, $\mathrm{t}-$ pipes and pipe crosses. Polish power plants usually operate in unit system, the characteristic feature of which are the following three pipelines: the primary steam pipeline, the re-superheated steam pipeline and the pipeline leading to the re-super heater.

Main steam pipelines operate in tough conditions, i.e. at high temperature and under high pressure as well as with periodically variable operating parameters. These pipes are subjected to mechanical load due to internal pressure, continuous load from deadweight, fasteners reactions, restrained thermal expansion as well as thermal load resulting from the temperature difference over the wall thickness as well as temperature difference during condensate creation at the commissioning of the unit [1].
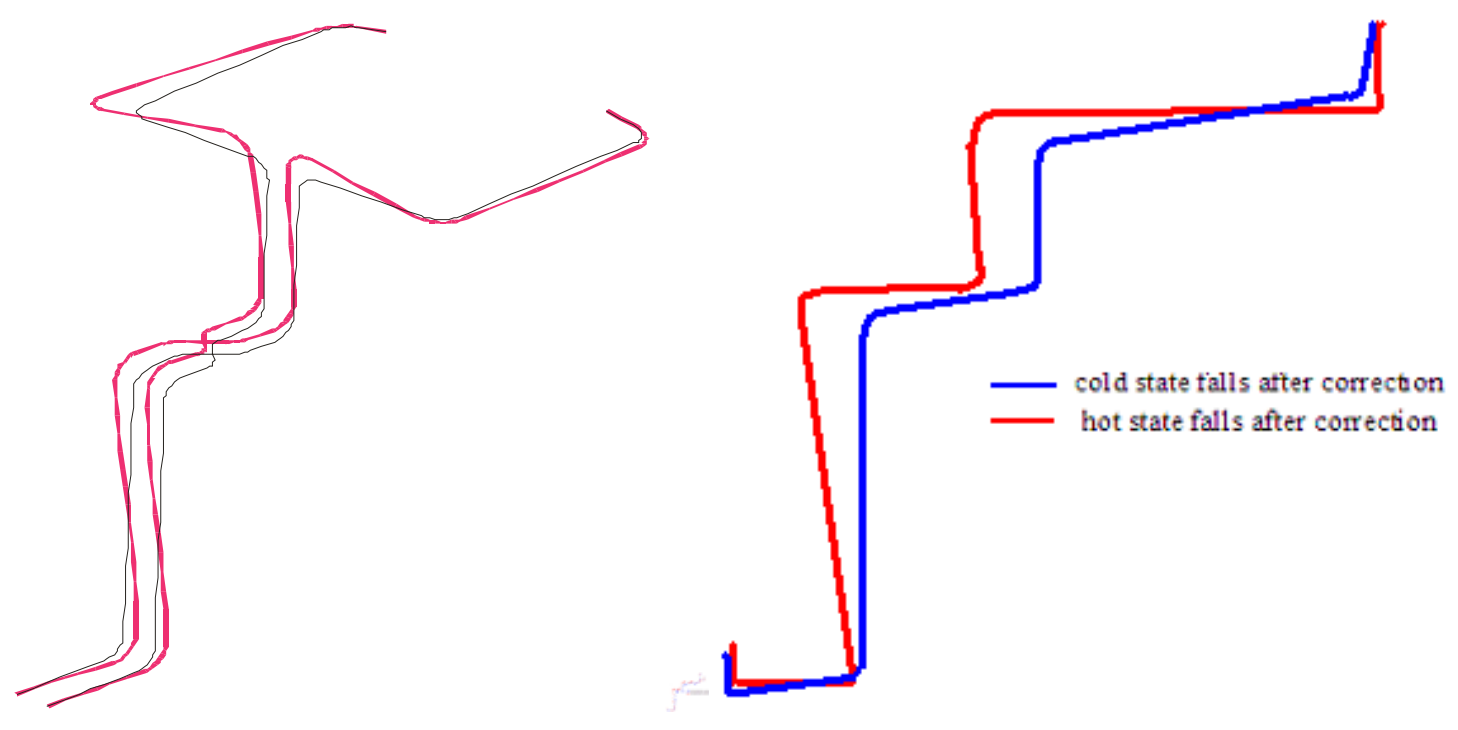

Fig. 2. Modeling of thermal expansion of the pipeline from the cold to the hot state 
Incorrect grade directions leading to condensate accumulation in pipelines cause high stress gradient over the wall thickness which in turn leads to higher material degradation rate. That process can be eliminated by maintaining appropriate position in cold state [fig.2]. In justified cases, it is recommended to correct pipeline grades.

Fatigue is a common cause for pre-mature damage of the structure and hence it is defined as a specific number of load cycles which can be resisted by given material. Hazard caused by failure of high-pressure pipelines may result in disastrous consequences for operation of the entire power plant as well as for its direct personnel. Hence to ensure safe pipeline operation, it is of highest importance to build them from steel grades characterised by high resistance to creep, brittle cracking, thermal and thermal-and-mechanical fatigue as well as by good weld ability.

\section{MICROSTRUCTURAL CHANGES OVER LONG TIME OPERATION}

Pipelines used in Polish power industry are mostly made of steel grades such as: 13HMF, 10H2M, X20CrMoV121, K18, 15HM (14MoV63, 10CrMo9-10, X20CrMoV121, St45.8I, 13CrMo44). More state-of-the-art materials used to manufacture pipes of boiler super-heaters, steam tanks, steam pressure tanks and pipelines designed to operate at the temperature range up to $650^{\circ} \mathrm{C}$ include steel grades such as P91 (X10CrMoVNb9-1) and P92 (X10CrMoVNb9-2). They shall replace currently used steel grades 13HMF (14MoV63) and 10H2M (10CrMo9-10). Degradation mechanism leading to damage of the material are well defined in case of long-time operation of the steel used in power plant pipelines. Materials characterised by operation time which is too short to evaluate material durability based on observation and operating tests are subject to shortened creep tests and tests performed under load which is characteristic for specific operation conditions of a given pipeline. Microstructural tests were performed using Nikon metallographic microscope for polished and etched (with 4\% nitral) samples. Drawings presented below show microstructure of the steel grade $13 \mathrm{HMF}$ after different periods of operation in primary steam pipeline.

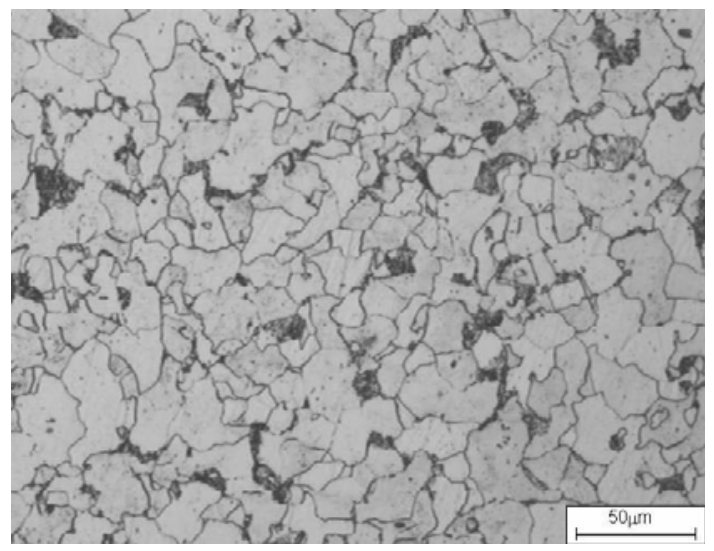

Fig. 3. Microstructure of the steel grade $13 \mathrm{HMF}$ in the initial state 


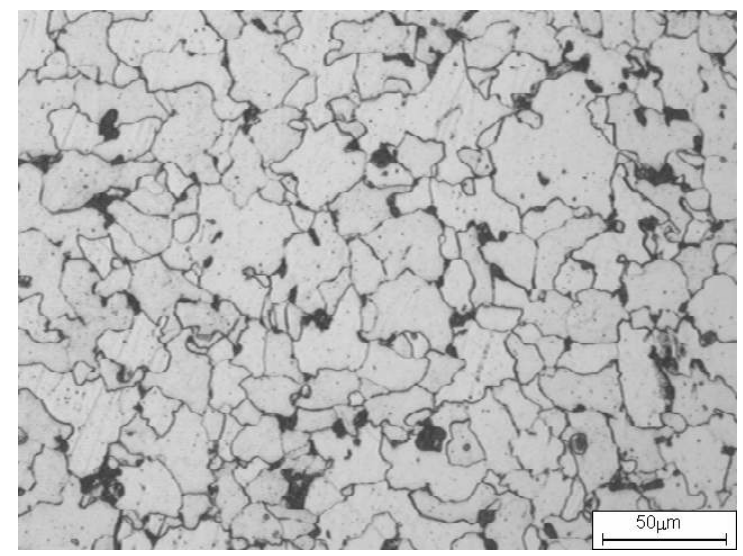

Fig. 4. Microstructure of the steel grade $13 \mathrm{HMF}$ after $\sim 60$ thousand operating hours

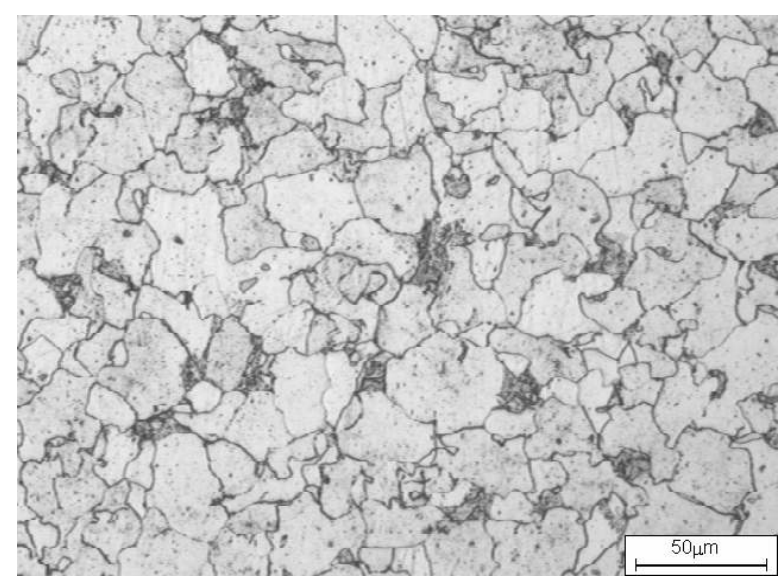

Fig. 5. Microstructure of the steel grade 13HMF after $\sim 160$ thousand operating hours

One can notice grain size growth in the exploited material (fig. 4 and 5) compared to the material in the initial state (fig.3). Degradation of the structure depends also on operating load. This applies particularly to the material of power industry pipelines subjected to internal pressure and mechanical stress causing local exceeding of the yield strength.

Table 1. Chemical composition of the steel grades $13 H M F, 10 H 2 M, X 20 C r M o V 121, P 91, P 92$

\begin{tabular}{|c|c|c|c|c|c|}
\hline Content [\% & 13HMF & 10H2M & X20CrMoV121 & P91 & P92 \\
\hline $\mathbf{C}$ & $0.10-0.18$ & $0.08-0.015$ & $0.17-0.23$ & $0.08-0.12$ & $0.07-0.13$ \\
\hline $\mathbf{M n}$ & $0.40-0.70$ & $0.40-0.670$ & $0.40-0.70$ & $0.30-0.60$ & $0.30-0.60$ \\
\hline $\mathbf{S i}$ & $0.15-0.35$ & $0.15-0.50$ & 0.5 & $0.20-0.50$ & $\max 0.50$ \\
\hline $\mathbf{P}(\mathbf{m a x})$ & 0.040 & 0.030 & 0.035 & 0.020 & 0.020 \\
\hline $\mathbf{S}(\mathbf{m a x})$ & 0.040 & 0.030 & 0.035 & 0.010 & 0.010 \\
\hline $\mathbf{C r}$ & $0.30-0.60$ & $2.0-2.5$ & $11.0-12.5$ & $8.0-9.5$ & $8.0-9.5$ \\
\hline $\mathbf{N i}$ & Max 0.30 & $\max 0.30$ & $0.3-0.8$ & $\max 0.40$ & $\max 0.40$ \\
\hline $\mathbf{M o}$ & $0.50-0.65$ & $0.9-1.1$ & $0.8-1.2$ & $0.85-1.05$ & $0.30-0.60$ \\
\hline $\mathbf{V}$ & $0.22-0.35$ & - & $0.25-0.35$ & $0.18-0.25$ & $0.15-0.25$ \\
\hline $\mathbf{C u}$ & Max 0.25 & $\max 0.25$ & - & $\max 0.3$ & - \\
\hline
\end{tabular}




\section{MECHANICAL PROPERTIES OF APPLIED MATERIALS}

Modern power plants in Europe are equipped with pipelines made of steel grade P92, which is characterised by better strength parameters than P91. While in new and modernized Polish power plants pipelines made of P91 are currently introduced.

Steel grade P92 was obtained by modification of chemical composition down to the content of about $9 \% \mathrm{Cr}$ as well as Mo and $\mathrm{V}$ with addition of $1-2 \%$ of tungsten and such micro-additives as niobium, nitrogen and boron.

Main advantages of P92 steel are as follows:

- $\quad$ very good creep properties,

- resistance to thermal fatigue, heat exchange and thermal expansion parameters allowing for frequent boiler start-ups and shut-downs,

- $\quad$ good weld ability, similar to the steel grade P91.

Table 2. Strength properties at standard temperature $20^{\circ} \mathrm{C}$ for steel grades: 13HMF, 10H2M, X20CrMoV121, P91, P92

\begin{tabular}{|c|c|c|c|c|c|}
\hline \multirow{2}{*}{ Steel properties } & \multicolumn{5}{|c|}{ Steel grade } \\
\cline { 2 - 6 } & $\mathbf{1 3}$ HMF & $\mathbf{1 0 H 2 M}$ & X20CrMoV121 & P91 & P92 \\
\hline $\mathrm{R}_{\mathrm{m}}[\mathrm{MPa}]$ & $490-690$ & $440-590$ & $690-840$ & $585-770$ & min. 620 \\
\hline $\mathrm{R}_{0.2 \min }[\mathrm{MPa}]$ & 365 & 265 & min. 490 & 415 & min. 440 \\
\hline $\mathrm{A}_{5 \min }[\%]$ longit. & 20 & 18 & 17 & 20 & 20 \\
\hline $\begin{array}{c}\text { Impact resistance } \\
\text { (longitudinal samples) } \\
\mathrm{KCV}\left[\mathrm{J} / \mathrm{cm}^{2}\right] \text { at } 20^{\circ} \mathrm{C}\end{array}$ & min. 90 & $\min .80$ & $\min .40$ & min. 40 & - \\
\hline $\mathrm{R}_{\mathrm{Z} / 100000}$ at $600^{\circ} \mathrm{C},[\mathrm{MPa}]$ & - & 24 & 60 & 98 & 132 \\
\hline
\end{tabular}

$\mathrm{R}_{\mathrm{m}}$ - tensile strength; $\mathrm{R}_{0,2 \min }$ - creep strength for $2 \%$ permanent deformation; $\mathrm{A}_{5 \min }$ - longitudinal elongation; $\mathrm{KCV}$ - impact strength; $\mathrm{R}_{\mathrm{Z} / 100000}$ - temporal creep strength (after $100000 \mathrm{~h}$ )

Before those steel grades were introduced to pipeline production, they had been subjected to material tests as well as test performed in laboratories and in real industrial conditions. The following graph shows creep resistance properties of the discussed grades of steel [2].

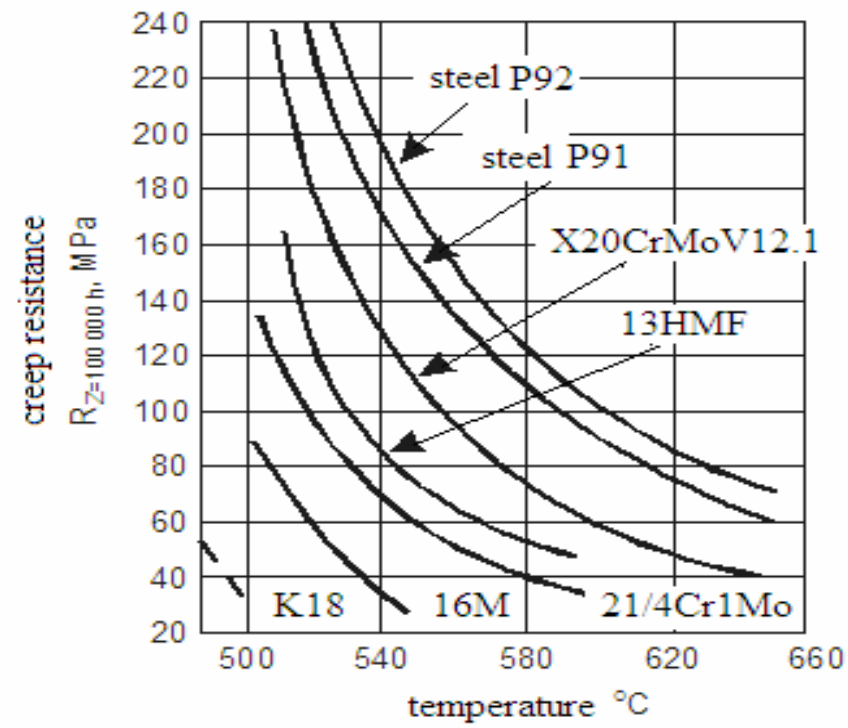

Fig. 6. Average creep resistance during specific time period for different steel grades 
Creep tests [2] were performed in ABB-CE (Windor), CT, USA using $6.4 \mathrm{~mm}$ thick and $100 \mathrm{~mm}$ long samples. The samples were machined in the pipeline circumference direction. The steel grade P92 was also subjected to those tests. The test results are presented in Table 3.

Table 3. Creep test results for steel grade P92

\begin{tabular}{|c|c|c|c|c|}
\hline $\begin{array}{c}\text { Temperature } \\
{\left[{ }^{\circ} \mathrm{C}\right]}\end{array}$ & $\begin{array}{c}\text { Stress } \\
{[\mathrm{MPa}]}\end{array}$ & $\begin{array}{c}\text { Rated deformation } \\
{[\%]}\end{array}$ & $\begin{array}{c}\text { Local deformation } \\
{[\%]}\end{array}$ & $\begin{array}{c}\text { Test duration } \\
{[\mathrm{h}]}\end{array}$ \\
\hline \multirow{4}{*}{600} & \multirow{4}{*}{162} & 0.5 & 0.5 & 138 \\
\cline { 3 - 5 } & & 1.0 & 1.0 & 342 \\
\cline { 3 - 5 } & & 2.0 & 2.5 & 10,609 \\
\cline { 3 - 5 } & & 5.0 & 3.5 & 10,297 \\
\cline { 3 - 5 } & & fracture & 3.0 & 10,586 \\
\hline \multirow{4}{*}{650} & \multirow{3}{*}{100} & 0.5 & 0.5 & 381 \\
\cline { 3 - 5 } & & 1.0 & 1.0 & 4,840 \\
\cline { 3 - 5 } & & 2.0 & 2.0 & 4,190 \\
\cline { 3 - 5 } & & 5.0 & 3.0 & 6,409 \\
\cline { 3 - 5 } & & fracture & 4.5 & 6,460 \\
\hline
\end{tabular}

Those results show that creep resistance of steel grade P92 decreases when the temperature increases. At the temperature of $600{ }^{\circ} \mathrm{C}$ the sample cracked under load of $162 \mathrm{MPa}$ after $10,609 \mathrm{~h}$, whereas at the temperature of $650{ }^{\circ} \mathrm{C}$ and load of $100 \mathrm{MPa}$ as early as after $6,460 \mathrm{~h}$.

Fig. 7 reveals two main microstructure changes of $\mathrm{P} 92$ steel caused by creep at $650^{\circ} \mathrm{C}$ : decreased dislocation density and growth of grain size [2]
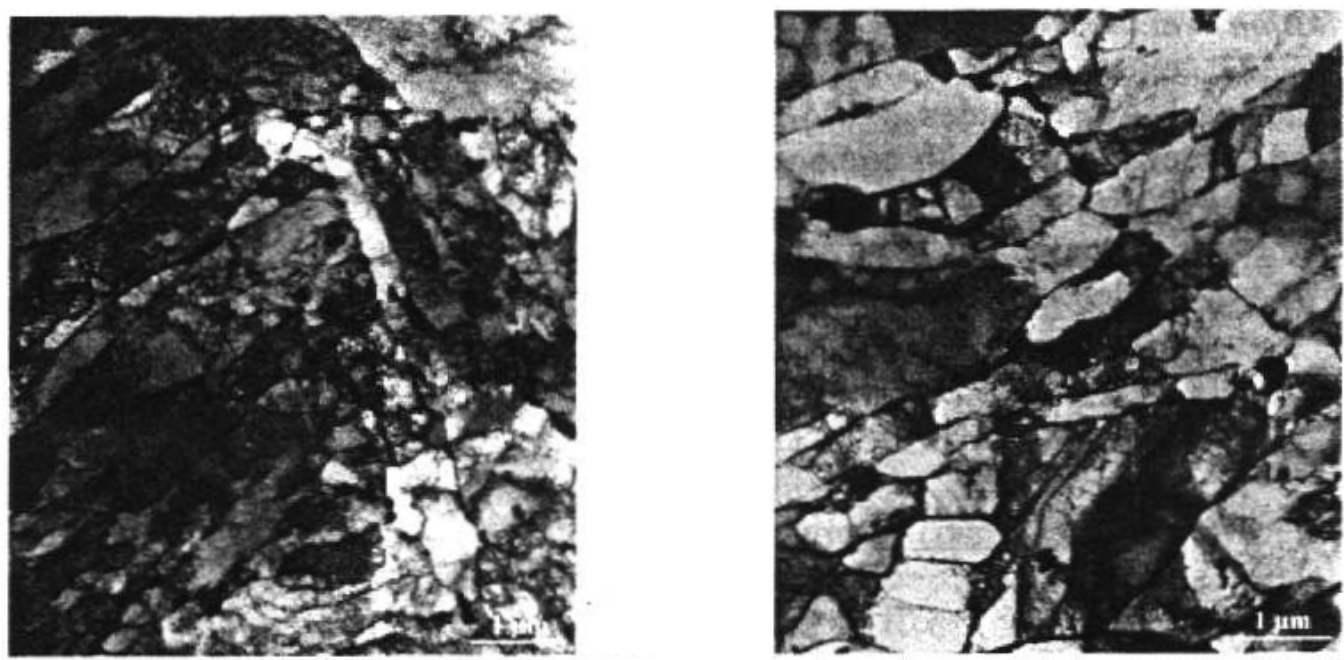

Fig. 7. Images of a thin TEM foil made of steel grade P92 in as-delivered state (on the left side) and after exposure to creep at $650^{\circ} \mathrm{C} / 100 \mathrm{MPa}$ for 4,190 hours up to $2.0 \%$ deformation (on the right side)

Microstructural changes occurring during first several thousand operating hours in creep conditions significantly influence the process of material deformation. Microstructural changes [3] occurring in steel grade P92 during creep tests include the following factors:

- Reduction of dislocation density, as the regeneration process, occurs initially in the martensite matrix. 
- Grain creation and growth,

- Coarsening of $\mathrm{M}_{23} \mathrm{C}_{6}$ carbides located mainly at boundaries of the primary austenite grains as well as at boundaries of martensite strip,

- Size changes of precipitated pure carbide, nitride and carbonitride composed mainly of $\mathrm{V}$ and $\mathrm{Nb}$,

Precipitate of Laves phase $\mathrm{Fe}_{2}(\mathrm{Mo}, \mathrm{W})$.

Piping weld seams are particularly prone to failures in form of fracture. Failure frequency analysis [4] for pipelines made of steel grade P91 and P92 taking into account weld fractures shows that pipelines made of steel grade P91 and P92 are resistant to weld fractures up to the temperature of $540^{\circ} \mathrm{C}$. Welds of steel grade P91 crack at the temperature of $600{ }^{\circ} \mathrm{C}$, whereas for steel grade $\mathrm{P} 92$ at the temperature of $625^{\circ} \mathrm{C}$.

Structural tests after long-time ageing at temperatures of 550, 600 and $650^{\circ} \mathrm{C}$ were also performed [3]. They proved that steel grade X10CrMoVNb91 which was aged longtime in the temperature range of $550 \div 650^{\circ} \mathrm{C}$ has relatively stable microstructure. Changes in the microstructure and chemical composition of grain boundary areas contribute to slight decrease of microhardness and hardness, amounting to $7 \div 13 \%$ and $4 \div 8 \%$ respectively, compared to the initial state. Slight decrease of microhardness and hardness is assisted by significant drop of impact resistance KCV amounting to $30 \div 42 \%$ compared to the initial state.

\section{STRESS AND HARDNESS TEST RESULTS}

Stress and hardness measurements were performed for exploited pipeline made of steel grade P91 after $40.000 \mathrm{~h}$ of service. Reduced stress amounted to $\sigma_{\text {red }}=26 \mathrm{MPa}$.

Stress tests were performed using Mathar strain gauge method. The temperature interference on tests results was eliminated. Hardness of strain gauge test areas was measured using a portable TIME hardness testing machine. Arcs were tested in tension zones. The test results are presented below in the table 4 .

Table 4. Hardness test results of the pipeline made of steel grade P91

\begin{tabular}{|c|c|c|c|}
\hline $\begin{array}{c}\text { No. of the } \\
\text { tested area }\end{array}$ & Tested component & $\begin{array}{c}\sigma \text { red. } \\
{[\mathrm{MPa}]}\end{array}$ & $\begin{array}{c}\text { Hardness } \\
{[\mathrm{HB}]}\end{array}$ \\
\hline 1 & horizontal arc $90^{\circ}$ & 48 & 209 \\
\hline 2 & horizontal arc $90^{\circ}$ & 55 & 181 \\
\hline 3 & vertical arc $90^{\circ}$ & 115 & 196 \\
\hline 4 & horizontal arc $90^{\circ}$ & 40 & 192 \\
\hline 5 & vertical $\operatorname{arc} 90^{\circ}$ & 105 & 194 \\
\hline 6 & vertical arc $90^{\circ}$ & 53 & 189 \\
\hline 7 & horizontal arc $45^{\circ}$ & 23 & 263 \\
\hline 8 & straight segment & 65 & 135 \\
\hline 9 & straight segment & 78 & 140 \\
\hline
\end{tabular}


Allowable stress determined according to the standard PN-79/M-34033 [5] for steel grade P91 at the design temperature which does not exceed the threshold temperature amounts to $218 \mathrm{MPa}$.

Allowable hardness according to the standard PN-92/M-34031 [6] amounts to $235 \mathrm{HB}$. In order to evaluate operational availability and to estimate the remaining safe operation time of power industry pipelines it is necessary to know the initial state of the material as well as the results of periodical strength tests performed during pipeline exploitation.

\section{CONCLUSIONS}

Materials currently used in Polish power industry for high temperature applications include such steel grades like K18, 15HM, 10H2M, 13HMF and X20CrMoV121. Those steel grades undergo relatively quick microstructure degradation in high temperature, which reduces their strength properties and shortens safe operation period of pipelines made of those materials.

As it is necessary to increase performance of power plants by their modernisation and as new power plants are planned, new steel grades of improved strength properties at high temperatures should be used. When introducing new steel grades, such as P91 and P92, in power plants, it is necessary to know strength parameters of the steel in as-delivered state and to monitor degradation processes after different periods of material operation, using samples taken from control sections designed at the facility design stage. This shall allow to maintain operation and diagnostic processes under safety requirements and to rationally plan overhaul life periods of the power plant pipelines.

\section{REFERENCES}

1. Mężyk D. The effect of pressure installation operation course in professional power sector on safety and reliability of their performance]. Conference Materials: Training seminar on development of material damage and laser-induced material modification, IPPT PAN Polish Academy of Sciences 2003, 193 - 204.

2. Hald J. Microstructure stability of steels P92 and P122, Proceedings of the 3rd Conference on Advances in Materials Technology for Fossil Power Plant, University of Wales, Swensea, 2001, 115 - 125.

3. Ennis P. Creep Strengthening Mechanisms in High Chromium Steels. Proceedings of the 3rd Conference on Advances in Materials Technology for Fossil Power Plant, University of Wales, Swensea, 2001, 187 - 197.

4. Middleton C. J., Brear J.M., Munson R., Viswanathan R. An assessment of the risk of Type IV cracking in welds to header, pipework and turbine components constructed from the advanced ferritic $9 \%$ and $12 \%$ chromium steel. Proceedings of the 3rd Conference on Advances in Materials Technology for Fossil Power Plant, University of Wales, Swensea, 2001, 69- 79.

5. PN-79/M-34033 - Water and steam pipelines. Pipe wall thickness calculations.

6. $\mathrm{PN}-92 / \mathrm{M}-34031$ - Hot water and steam pipelines. General requirements and testing procedures. 